\title{
TRIAGEM DE SUPORTES ORGÂNICOS E PROTOCOLOS DE ATIVAÇÃO NA IMOBILIZAÇÃO E ESTABILIZAÇÃO DE LIPASE DE Thermomyces lanuginosus
}

\author{
Adriano A. Mendes* \\ Universidade Federal de São João Del-Rei, Campus Sete Lagoas, CP 56, 35701-970 Sete Lagoas - MG, Brasil \\ Heizir F. de Castro \\ Departamento de Engenharia Química, Escola de Engenharia de Lorena, Universidade de São Paulo, CP 116, $12602-810$ Lorena \\ - SP, Brasil \\ Raquel de L. C. Giordano \\ Departamento de Engenharia Química, Universidade Federal de São Carlos, CP 676, 13560-970 São Carlos - SP, Brasil
}

Recebido em 1/5/12; aceito em 21/8/12; publicado na web em 24/1/13

\begin{abstract}
SCREENING OF ORGANIC SUPPORTS AND ACTIVATION PROTOCOLS FOR IMMOBILIZATION AND STABILIZATION OF LIPASE FROM Thermomyces lanuginosus. Lipase from Thermomyces lanuginosus was covalently immobilized on activated poly-hydroxybutyrate, sugarcane bagasse and the chemically modified hybrid hydrogel chitosan-alginate prepared by different strategies. Among the tested supports, chitosan-alginate chemically modified with 2,4,6-trinitrobenzenesulfonic acid rendered derivatives with the highest hydrolytic activity and thermal-stability, 45-fold more stable than soluble lipase and was then selected for further studies. The $\mathrm{pH}$ of maximum activity was similar for both immobilized and free lipase ( $\mathrm{pH}$ 8.0) while optimum temperature was $5-10{ }^{\circ} \mathrm{C}$ higher for the immobilized lipase. Higher yields in the butyl butyrate synthesis were found for the derivatives prepared by activation with glycidol and epichlorohydrin.
\end{abstract}

Keywords: covalent attachment; lipase; organic supports.

\section{INTRODUÇÃO}

Lipases (triacilglicerol éster hidrolases - E.C. 3.1.1.3) são enzimas hidrolíticas que atuam na interface orgânica-aquosa, catalisando a hidrólise de lipídeos para liberar ácidos orgânicos e glicerol, podendo a reação inversa (síntese) ocorrer em ambientes não aquosos. Este fenômeno é devido à sua capacidade de utilização em uma ampla gama de substratos, à sua estabilidade na presença de solventes orgânicos e à sua quimio, regio e enantiosseletividade. As lipases têm sido amplamente empregadas na produção de fármacos, emulsificantes, alimentos, perfumaria, diagnósticos médicos, síntese de compostos opticamente ativos, resolução de racematos, produção de aromas e fragrâncias, modificações de lipídeos para a produção de biodiesel e lipídeos estruturados e no pré-tratamento de efluentes com elevado teor de lipídeos gerados pelas indústrias de alimentos. ${ }^{1-9}$

Para que as lipases sejam empregadas em um determinado processo industrial, é necessária a sua reutilização e o aumento de sua estabilidade térmica. ${ }^{10,11}$ Diferentes técnicas de imobilização têm sido desenvolvidas para fornecer estabilidade às enzimas e facilitar a sua recuperação e reutilização. ${ }^{12-35} \mathrm{~A}$ seleção do melhor método de imobilização deve ser baseada em parâmetros como atividade global do imobilizado, características de regeneração e inativação, custo do procedimento de imobilização, toxicidade dos reagentes e propriedades finais desejadas para a enzima imobilizada. ${ }^{25,26,32-35}$

Diferentes protocolos têm sido empregados na imobilização e estabilização de lipases como adsorção hidrofóbica, adsorção iônica, encapsulação em matrizes orgânicas, inorgânicas e em matrizes híbridas e por ligação covalente unipontual e multipontual em suportes previamente ativados. ${ }^{12-35}$ Dentre os protocolos de imobilização disponíveis, ligação covalente multipontual é um método bastante atrativo na estabilização de enzimas. A imobilização de enzimas em suportes com elevada concentração de grupos glioxil

*e-mail: mendes@ufsj.edu.br (grupos aldeído) permite a obtenção de derivados termoestáveis decorrentes da intensa interação dos resíduos lisina da enzima com os grupos glioxil do suporte, com a formação de bases de Schiff $(-\mathrm{C}=\mathrm{N}-) \cdot{ }^{12,17-19,21}$ Esta estabilização é devido à boa congruência geométrica de alguns suportes, como glioxil-agarose, que possibilita um correto alinhamento entre a enzima e o suporte, contribuindo para a formação de multi-interações que aumentam significativamente a estabilidade térmica dos derivados preparados. ${ }^{12,17,18}$ Muitas enzimas têm sido estabilizadas em suportes glioxil, com atividade recuperada variando de 60 a $100 \%$ e elevada estabilização térmica, na maioria dos casos superiores a $10^{3} \mathrm{e}$, em certos casos, estes valores são superiores a $10^{5} \cdot{ }^{17-19} \mathrm{O}$ suporte mais empregado na imobilização de enzimas por ligação covalente multipontual via glioxil é o gel de agarose,,$^{12,17,18,25-27,29,30}$ um suporte de alto custo e disponível comercialmente. ${ }^{36}$ Entretanto, outros suportes de baixo custo alternativos à agarose, como quitosana e hidrogeis híbridos, têm sido empregados na imobilização e estabilização de enzimas de interesse industrial, apresentando resultados bastante atrativos. ${ }^{24}$

Neste sentido, o objetivo do presente trabalho consistiu na triagem de suportes de baixo custo e protocolos de ativação para a preparação de derivados com elevada atividade catalítica e estabilidade térmica empregando a lipase microbiana de Thermomyces lanuginosus. Esta lipase tem sido amplamente empregada em reações em meio orgânico e aquoso para a obtenção de produtos de grande interesse industrial, como concentrados de ácidos graxos livres por hidrólise seletiva de diferentes óleos e gorduras, biodiesel, lipídeos estruturados, ésteres aromatizantes, formulação de detergentes, resolução de misturas racêmicas, degradação de polímeros e no pré-tratamento de efluentes com elevados teores de lipídeos. ${ }^{5,21-23}$ A lipase foi imobilizada por ligação covalente multipontual em bagaço de cana-de-açúcar, partículas de poli-hidróxibutirato (PHB) e hidrogéis híbridos de quitosana-alginato. Com o propósito de aumentar o tamanho de poros dos hidrogéis híbridos, foi adotada a técnica de coimobilização de células de leveduras (Saccharomyces 
cerevisiae), seguida de ruptura celular. A estratégia de coimobilização de leveduras em hidrogéis híbridos de quitosana, seguida de ruptura celular tem melhorado sensivelmente a atividade catalítica e estabilização térmica de algumas enzimas, como quimotripsina. ${ }^{19}$ Neste trabalho, foi também empregado o procedimento de modificação química dos hidrogéis híbridos de quitosana-alginato com diferentes agentes, tais como ácido 2,4,6 trinitrobenzenossulfônico (TNBS) e laurinaldeído com a finalidade de aumentar a hidrofobicidade destes suportes e, consequentemente, melhorar a difusão de substratos hidrofóbicos (azeite de oliva) nos interstícios do suporte. Com relação aos suportes PHB e bagaço de cana, a aplicação destas matrizes na imobilização/estabilização de lipases ainda é pouco reportada pela literatura especializada. As propriedades catalíticas dos derivados preparados foram determinadas na hidrólise do azeite de oliva emulsificado com goma arábica. Os derivados com maior atividade catalítica e estabilidade térmica foram selecionados e caracterizadas as suas propriedades catalíticas em meio aquoso quanto à influência do $\mathrm{pH}$ e temperatura e em meio orgânico na síntese de éster aromatizante butirato de butila (aroma de abacaxi).

\section{PARTE EXPERIMENTAL}

\section{Materiais}

Foi utilizada a preparação de lipase de Thermomyces lanuginosus (LTL), com atividade de 191,2 U/mg de proteína, gentilmente fornecida pela empresa Novozymes S.A. (Araucária, PR). Quitosana 85,2\% de desacetilação foi adquirida da Polymar S.A. (Fortaleza, CE), alginato de sódio adquirido comercialmente da Vetec (São Paulo, SP), poli-hidróxibutirato (PHB) da PHB Brasil (São Paulo, SP) e bagaço de cana-de-açúcar da Usina São Martinho (Pradópolis, SP). Fermento de pão (S. cerevisiae) foi adquirido comercialmente da Oetker. Glicidol (GLI), epicloridrina (EPI), ácido 2,4,6 trinitrobenzenossulfônico (TNBS), laurinaldeído (LAU), n-butanol e ácido butírico foram adquiridos da Sigma-Aldrich (St. Louis, EUA). Glutaraldeído (GLU) $25 \%$ e etilenodiamina (EDA) foram adquiridos da Vetec (São Paulo, SP) e goma arábica da Synth (São Paulo, SP). Azeite de oliva de baixa acidez foi adquirido no comércio local (Carbonell). Todos os outros reagentes utilizados foram de grau analítico.

\section{Determinação da concentração de proteína}

A concentração de proteína foi quantificada pelo método de Bradford, ${ }^{37}$ empregando albumina sérica bovina (BSA) como padrão.

\section{Determinação da atividade hidrolítica}

A atividade hidrolítica foi determinada pelo método de hidrólise da emulsão de azeite de oliva, conforme metodologia adaptada de Soares et al. ${ }^{38}$ A solução de substrato foi preparada pela emulsão de $25 \mathrm{~g}$ de azeite de oliva e $75 \mathrm{~g}$ de solução de goma arábica a $3 \%$ $\mathrm{m} / \mathrm{m}$. Em frascos Erlenmeyer de $125 \mathrm{~mL}$ foram adicionadas $5 \mathrm{~mL}$ da solução de substrato, $5 \mathrm{~mL}$ de solução tampão fosfato de sódio (100 $\mathrm{mM}, \mathrm{pH} 8,0$ ) e adicionados $0,1 \mathrm{~g}$ de derivado ou $0,1 \mathrm{mg}$ de enzima nas formas imobilizada e solúvel, respectivamente. Os frascos foram incubados a $37^{\circ} \mathrm{C}$ por $5 \mathrm{~min}$, em banho termostatizado com agitação de $200 \mathrm{rpm}$. A reação foi finalizada pela adição de $10 \mathrm{~mL}$ de etanol comercial $(92,5 \% \mathrm{v} / \mathrm{v})$ e os ácidos graxos liberados quantificados por titulação com solução de $\mathrm{NaOH} 20 \mathrm{mM}$, empregando fenolftaleína como indicador. Uma unidade de atividade foi definida como a quantidade de enzima que libera $1 \mu \mathrm{mol}$ de ácido graxo por minuto de reação, nas condições do ensaio.

\section{Preparação dos hidrogéis híbridos quitosana-alginato}

Os hidrogéis híbridos foram preparados, conforme metodologia descrita por Mendes et al.. ${ }^{21}$ Os hidrogéis híbridos de quitosana-alginato contendo leveduras ( $S$. cerevisiae) coimobilizadas na concentração de $10 \% \mathrm{~m} / \mathrm{m}$ seguido de ruptura celular com sabão em pó foram preparados conforme metodologia descrita por Adriano et al. ${ }^{19}$ Os hidrogéis obtidos foram lavados com água destilada, filtrados a vácuo e estocados sob refrigeração.

\section{Modificação química dos hidrogéis híbridos quitosana-alginato com TNBS e laurinaldeído}

Os hidrogéis híbridos quitosana-alginato foram modificados quimicamente com TNBS em pH 10,05 (tampão bicarbonato de sódio $100 \mathrm{mM}$ ) por $24 \mathrm{~h} \mathrm{a} 25^{\circ} \mathrm{C}$, conforme metodologia descrita por Mendes et al.. ${ }^{21}$ Hidrogel híbrido quitosana-alginato modificado quimicamente com laurinaldeído foi preparado empregando diferentes concentrações do agente $(1,3$ e $5 \%$ m/m). A reação de modificação química foi realizada em tampão fosfato de sódio pH 7,0 (200 mM) por $1 \mathrm{~h}$ a $25{ }^{\circ} \mathrm{C}$. Os hidrogéis híbridos modificados quimicamente pelos dois procedimentos foram lavados com água destilada, filtrados a vácuo e estocados sob refrigeração.

\section{Preparação de glioxil-suportes por ativação com glicidol e epicloridrina}

$10 \mathrm{~g}$ dos suportes poli-hidróxibutirato (PHB), bagaço de cana e hidrogéis híbridos quitosana-alginato-TNBS preparados com ou sem coimobilização de leveduras foram lavados com água destilada e filtrados a vácuo. Após esta etapa, foram adicionados $3 \mathrm{~mL}$ de água destilada aos suportes e $5 \mathrm{~mL}$ de solução de $\mathrm{NaOH}$ 1,7 M contendo $0,15 \mathrm{~g}$ de boro-hidreto de sódio $\left(\mathrm{NaBH}_{4}\right)$, em banho de gelo. Em seguida, adicionaram-se lentamente $3,43 \mathrm{~mL}$ de glicidol. ${ }^{39}$ Para a epicloridrina, foram adicionados aos $10 \mathrm{~g}$ de suporte, $90 \mathrm{~mL}$ de solução de $\mathrm{NaOH} 2 \mathrm{M}$ contendo $0,6 \mathrm{~g}$ de $\mathrm{NaBH}_{4}$ em banho de gelo. Em seguida, adicionou-se lentamente $10 \mathrm{~mL}$ de epicloridrina. ${ }^{40} \mathrm{As}$ suspensões foram mantidas sob agitação mecânica em recipiente aberto por $15 \mathrm{~h}$, em ambos os sistemas. Os suportes previamente ativados (gliceril-suportes) foram lavados exaustivamente com água destilada e filtrados a vácuo. Para a obtenção de glioxil-suportes, 10 g de gliceril-suportes, previamente obtidos por ativação via glicidol e epicloridrina, foram suspensos em $100 \mathrm{~mL}$ de água destilada e adicionados $100 \mu$ moles de periodato de sódio por grama de poli-hidróxibutirato (PHB) e bagaço de cana e 300 umoles por grama de hidrogéis híbridos quitosana-alginato-TNBS preparados pelos diferentes procedimentos (com ou sem coimobilização de leveduras). A oxidação foi mantida sob suave agitação por $2 \mathrm{~h}$ a $25^{\circ} \mathrm{C}$. Em seguida, os suportes ativados (glioxil-suportes) foram lavados exaustivamente com água bidestilada, filtrados a vácuo e estocados sob refrigeração.

\section{Preparação de suportes glioxil-amino-glutaraldeído}

A preparação de suportes glioxil-amino-glutaraldeído foi realizada a partir de suportes glioxil ativados com glicidol. ${ }^{41}$ Inicialmente, $40 \mathrm{~mL}$ de solução de etilenodiamina (EDA) $2 \mathrm{M}$ a pH 10,0 foram adicionados a $10 \mathrm{~g}$ de glioxil-suportes ativados com glicidol (glioxil-bagaço de cana e glioxil-PHB) e mantido sob agitação por $2 \mathrm{~h}$. Em seguida, $0,57 \mathrm{~g}$ de boro-hidreto de sódio $\left(\mathrm{NaBH}_{4}\right)$ foi adicionado ao sistema e mantido por mais $2 \mathrm{~h}$ sob agitação branda em frasco aberto à temperatura ambiente. Foram adicionados aos suportes aminados (glioxil-amino), previamente lavados com água destilada e filtrados sob vácuo, solução de glutaraldeído a $25 \%(16,8 \mathrm{~mL})$ diluída em 
tampão fosfato de sódio $200 \mathrm{mM}$ pH 7,0 (11,2 mL) e mantidos sob agitação a $25{ }^{\circ} \mathrm{C}$ por $18 \mathrm{~h}$. Os suportes glioxil-amino-glutaraldeído preparados foram lavados exaustivamente com água destilada, filtrados a vácuo e estocados sob refrigeração.

\section{Ativação de hidrogéis híbridos quitosana-alginato-TNBS com glutaraldeído}

Foram adicionados a $10 \mathrm{~g}$ do hidrogel híbrido quitosana-alginato modificado quimicamente com TNBS, $11,2 \mathrm{~mL}$ de solução tampão fosfato de sódio $200 \mathrm{mM}$ (pH 7,0) e 16,8 mL de uma solução 25\% de glutaraldeído e as suspensões foram mantidas sob agitação por $1 \mathrm{~h}$ à temperatura ambiente. ${ }^{21}$ Os hidrogéis híbridos ativados foram lavados com água destilada, filtrados a vácuo e estocados sob refrigeração.

\section{Protocolo de imobilização covalente multipontual da lipase nos suportes ativados}

A imobilização da lipase foi realizada em tampão bicarbonato de sódio $100 \mathrm{mM} \mathrm{pH} \mathrm{10,05} \mathrm{empregando} \mathrm{carregamento} \mathrm{de} \mathrm{proteína} \mathrm{de}$ $5 \mathrm{mg} / \mathrm{g}$ de suporte. A solução enzimática foi adicionada ao suporte na relação 1:10 (suporte:solução enzimática). A suspensão foi mantida sob agitação mecânica a $25{ }^{\circ} \mathrm{C}$ por um período de $12 \mathrm{~h}$. Após a imobilização, foram quantificadas, no sobrenadante, a concentração de proteína e atividade hidrolítica residual. Em seguida, os derivados preparados foram lavados exaustivamente com água destilada, filtrados e estocados sob refrigeração.

\section{Cálculo dos parâmetros de imobilização}

A concentração de proteína imobilizada (PI) foi quantificada com base na concentração de proteína inicialmente oferecida e a concentração de proteína residual presente no sobrenadante após a imobilização. A atividade recuperada (AR) foi determinada pela relação entre a atividade hidrolítica dos derivados $\left(\mathrm{AH}_{\text {der. }}\right)$ e a atividade desaparecida no sobrenadante após a imobilização. A atividade específica (AE) foi calculada pela relação entre a atividade hidrolítica dos derivados preparados e a concentração de proteína imobilizada. $\mathrm{O}$ fator de estabilidade (FE) foi calculado pela relação entre o tempo de meia-vida da lipase imobilizada e a lipase solúvel, incubados a $70{ }^{\circ} \mathrm{Ce} \mathrm{pH} 8,0 . .^{21,22}$

\section{Caracterização das propriedades bioquímicas de LTL solúvel e imobilizada}

A influência da temperatura na atividade hidrolítica da lipase solúvel e imobilizada em hidrogel híbrido quitosana-alginato-TNBS ativado por diferentes protocolos foi verificada empregando-se a reação de hidrólise do azeite de oliva em $\mathrm{pH}$ 8,0 na faixa de temperatura entre 30 a $90{ }^{\circ} \mathrm{C}$. A influência do $\mathrm{pH}$ foi avaliada empregando-se a reação de hidrólise do azeite de oliva emulsificado na temperatura ótima para cada preparação, em tampão fosfato de sódio $100 \mathrm{mM}$ na faixa de $\mathrm{pH}$ de 5,0 a 9,0, em intervalos de 0,5.

\section{Síntese de butirato de butila}

A síntese de butirato de butila foi realizada pela esterificação de $n$-butanol (100 mM) com ácido butírico (100 mM) em heptano ( $10 \mathrm{~mL}$ de substrato) catalisada por $1,0 \mathrm{~g}$ de derivado preparado por imobilização da lipase em quitosana-alginato-TNBS ativada por diferentes protocolos, conforme metodologia adaptada de Soares et al. ${ }^{38}$ As reações foram conduzidas em incubadora rotativa por $24 \mathrm{he}$ agitação de $200 \mathrm{rpm}$ a $37^{\circ} \mathrm{C}$. A conversão em ésteres foi estimada pela concentração de ácido butírico consumido na reação por titulação com solução de $\mathrm{NaOH} 20$ mM empregando fenolftaleína como indicador.

\section{RESULTADOS E DISCUSSÃO}

\section{Preparação de derivados ativos e estáveis termicamente de LTL}

De acordo com os resultados sumarizados na Tabela 1 , os suportes previamente ativados com glutaraldeído forneceram maior concentração de proteína imobilizada. Este efeito tem sido amplamente reportado na literatura. ${ }^{19,21,22,28,30} \mathrm{~A}$ ativação de suportes aminados com elevada concentração de glutaraldeído, conforme realizada no presente trabalho, é efetuada por dímeros de moléculas de glutaraldeído, gerando a formação de braços espaçadores com 10 átomos de carbono. A ativação de suportes aminados com baixa concentração de glutaraldeído gera braços espaçadores com apenas 1 molécula do agente ( 5 átomos de carbono) que são menos reativos. ${ }^{30}$ Consequentemente, o aumento da cadeia carbônica destes braços espaçadores aumenta a sua reatividade e permite maior concentração de enzima imobilizada. ${ }^{19,21,22,28,30}$ Suportes ativados via glutaraldeído sofrem ataque nucleofílico de grupos amino terminal (pKa 6,0-7,0) e dos resíduos lisina $\left(\mathrm{pKa}=10,7\right.$ ) da enzima. ${ }^{19,21,22,28}$ Outros grupos nucleofílicos da enzima como tióis, hidroxilas e imidazóis também reagem com este agente, o que não é verificado para suportes ativados via glioxil (glicidol e epicloridrina) que reagem seletivamente com grupos amino desprotonados dos resíduos lisina situados na superfície das enzimas. ${ }^{19}$ Dentre os suportes testados, foi encontrada máxima concentração de proteína imobilizada para os hidrogéis híbridos de quitosana-alginato-TNBS, entre 3,54 e 4,10 mg de proteína/g de gel para os suportes preparados sem e com a coimobilização de leveduras, respectivamente. Entre os derivados preparados por ativação via glutaraldeído, aqueles obtidos por imobilização da lipase em PHB e bagaço de cana apresentaram menor concentração de enzima imobilizada, 1,74 e 1,97 mg/g, respectivamente. A concentração de enzima imobilizada para os suportes ativados via glioxil (ativação com glicidol e epicloridrina) foi sensivelmente inferior aos suportes ativados via glutaraldeído. A menor reatividade dos grupos glioxil é decorrente do tamanho do braço espaçador obtido, com apenas 2 átomos de carbono, que por impedimento estérico, por estarem mais próximos do microambiente do suporte, reduz a capacidade de imobilizar concentrações elevadas de enzimas. ${ }^{22}$ Outro importante fator é a baixa concentração de resíduos lisina na superfície de LTL (apenas 7 resíduos) que reduz a porcentagem de imobilização. ${ }^{29}$ Vale ressaltar que a imobilização de enzimas em géis glioxil é realizada somente pelo ataque nucleofílico dos grupos amino dos resíduos lisina aos grupos aldeído do suporte. ${ }^{18,19}$ Dentre os derivados preparados via glioxil, apenas aqueles provenientes de hidrogéis híbridos sem a coimobilização de leveduras é que apresentaram maior concentração de enzima imobilizada ( $1,80 \mathrm{mg} / \mathrm{g}$ de gel), duas vezes inferior ao gel preparado com ativação glutaraldeído. A imobilização de LTL em PHB previamente ativada com epicloridrina não foi realizada, devido à parcial solubilização do suporte na presença do agente de ativação.

Os derivados com elevada atividade hidrolítica foram obtidos por ativação com glicidol e epicloridrina. Embora estes agentes permitam menor capacidade de imobilização de enzimas, o acesso das moléculas do substrato aos sítios ativos da enzima imobilizada é maior, devido aos menores efeitos de difusão no microambiente dos suportes. ${ }^{21,22}$ Derivados preparados por ativação com glutaraldeído resultaram em menor atividade catalítica, em decorrência da elevada reatividade do agente de ativação que pode distorcer a estrutura ativa de algumas moléculas de enzimas ou pela má orientação destas moléculas de enzimas durante a imobilização 
Tabela 1. Propriedades catalíticas dos derivados de LTL preparados por imobilização em suportes orgânicos ativados por diferentes protocolos. Carga enzimática oferecida de $5 \mathrm{mg}$ de proteína/g de suporte

\begin{tabular}{|c|c|c|c|c|c|c|c|}
\hline \multirow[b]{2}{*}{ Suportes } & \multirow{2}{*}{$\begin{array}{l}\text { Agentes de } \\
\text { ativação }\end{array}$} & \multicolumn{6}{|c|}{ Propriedades catalíticas } \\
\hline & & $\begin{array}{c}\text { PI } \\
\text { (mg/g de suporte) }\end{array}$ & $\begin{array}{c}\mathrm{AH}_{\text {der. }} \\
\text { (U/g de suporte) }\end{array}$ & $\begin{array}{c}\mathrm{AE} \\
\left(\mathrm{U} / \mathrm{mg}_{\mathrm{PI}}\right)\end{array}$ & $\begin{array}{l}\mathrm{AR} \\
(\%)\end{array}$ & $\begin{array}{l}\mathrm{t}_{1 / 2} \\
(\mathrm{~h}) \\
\end{array}$ & FE \\
\hline \multirow[t]{2}{*}{ PHB } & GLI & 0,99 & 76,7 & 77,5 & 40,7 & 1,47 & 22,5 \\
\hline & GLU & 1,74 & 76,8 & 44,1 & 23,1 & 1,06 & 16,2 \\
\hline \multirow[t]{3}{*}{ Bagaço de cana } & GLI & 1,27 & 183,6 & 144,6 & 75,5 & 1,16 & 17,7 \\
\hline & EPI & 1,27 & 191,8 & 151,0 & 78,8 & 1,25 & 19,1 \\
\hline & GLU & 1,97 & 79,5 & 40,3 & 21,1 & 0,87 & 13,2 \\
\hline \multirow{3}{*}{$\begin{array}{l}\text { Quitosana- } \\
\text { alginato-LAU }\end{array}$} & $\mathrm{GLI}^{\mathrm{a}}$ & 1,06 & 54,8 & 51,7 & 22,7 & 1,18 & 18,0 \\
\hline & $\mathrm{GLI}^{\mathrm{b}}$ & 1,18 & 71,2 & 60,3 & 29,1 & 1,58 & 24,2 \\
\hline & $\mathrm{GLI}^{\mathrm{c}}$ & 1,36 & 87,7 & 64,5 & 36,4 & 1,59 & 24,5 \\
\hline \multirow{3}{*}{$\begin{array}{l}\text { Quitosana- } \\
\text { alginato-TNBS }^{\mathrm{d}}\end{array}$} & GLI & 1,81 & 234,6 & 129,6 & 67,8 & 3,93 & 45,3 \\
\hline & EPI & 1,84 & 217,0 & 117,9 & 61,7 & 3,99 & 45,2 \\
\hline & GLU & 3,54 & 213,7 & 60,4 & 32,6 & 3,89 & 44,2 \\
\hline \multirow{3}{*}{$\begin{array}{l}\text { Quitosana- } \\
\text { alginato-levedura- } \\
\text { TNBS }^{\mathrm{e}}\end{array}$} & GLI & 1,20 & 65,8 & 54,8 & 21,4 & 2,91 & 33,1 \\
\hline & EPI & 1,25 & 76,7 & 61,4 & 25,6 & 2,64 & 30,0 \\
\hline & GLU & 4,10 & 109,6 & 26,7 & 38,8 & 2,34 & 26,6 \\
\hline
\end{tabular}

a-modificação química de quitosana-alginato com laurinaldeído na concentração de $1 \% \mathrm{~m} / \mathrm{m}$. b - modificação química de quitosana-alginato com laurinaldeído na concentração de $3 \% \mathrm{~m} / \mathrm{m}$. c - modificação química de quitosana-alginato com laurinaldeído na concentração de $5 \% \mathrm{~m} / \mathrm{m}$. d - hidrogel híbrido quitosanaalginato preparado por modificação química com TNBS. e - hidrogel híbrido quitosana-alginato-levedura - hidrólise com sabão em pó, seguida de modificação química com TNBS. PI - concentração de proteína imobilizada (mg/g de suporte); $\mathrm{AH}_{\text {der. }}$ - atividade hidrolítica dos derivados (U/g de suporte); $\mathrm{AE}$ - atividade hidrolítica específica (U/mg PI); AR - atividade recuperada (\%); $\mathrm{t}_{1 / 2}$ - tempo de meia-vida (h); FE - fator de estabilidade

(imobilização randômica). ${ }^{21,22}$ Foi verificada elevada atividade hidrolítica na imobilização de LTL em hidrogéis híbridos de quitosana-alginato-TNBS preparados sem a coimobilização de leveduras, que variou de 213,7 a 234,6 U/g de gel. Estes resultados podem ser atribuídos à boa congruência geométrica do suporte que permite um correto alinhamento das moléculas de enzimas na superfície do suporte, ou seja, melhora o contato enzima-suporte e reduz possíveis efeitos de distorção na estrutura tridimensional da enzima. ${ }^{21}$ Vale ressaltar que a estratégia de coimobilização de células de leveduras durante a preparação de hidrogéis híbridos, seguida de ruptura celular, objetivou a formação de maiores diâmetros de poros nestas matrizes. Entretanto, a imobilização de LTL nestas matrizes não gerou efeitos positivos na atividade catalítica da enzima, bem como a estabilização térmica. A atividade catalítica dos derivados preparados por imobilização em hidrogel híbrido seguida de ruptura celular foi reduzida drasticamente devido, provavelmente, à presença de material celular nos interstícios da matriz que limitou o acesso do substrato aos poros do suporte. Desta forma, considera-se que a estratégia de coimobilização de leveduras e ruptura celular (quitosana-alginato-levedura-TNBS) não foi satisfatória para a preparação de derivados ativos e termoestáveis de LTL. De acordo com a Tabela 1, a máxima atividade hidrolítica obtida para este suporte foi de 109,6 U/g (ativação via glutaraldeído), duas vezes inferior aos derivados preparados sem a coimobilização de leveduras (quitosana-alginato-TNBS). A imobilização de LTL em bagaço de cana ativado com glicidol e epicloridrina obteve resultados bastante promissores em termos de atividade hidrolítica, 183,9 e 191,8 U/g, respectivamente, ligeiramente inferior à quitosana-alginato-TNBS, como mostrado na Tabela 1. A elevada atividade hidrolítica destes derivados é atribuída ao microambiente altamente hidrofóbico do suporte. Com base em estudos reportados na literatura, lipases possuem alta afinidade por suportes hidrofóbicos. ${ }^{17,21,23-25,27} \mathrm{~A}$ imobilização de LTL em matrizes hidrofóbicas, como bagaço de cana e hidrogel híbrido quitosana-alginato-TNBS, corrobora estes estudos. No presente trabalho, também foi testada a imobilização covalente da enzima em outros dois suportes hidrofóbicos como partículas de PHB e o hidrogel híbrido quitosana-alginato modificado quimicamente com laurinaldeído (LAU), um aldeído alifático monofuncional com 12 átomos de carbono. Entretanto, a atividade catalítica dos derivados preparados foi 3 vezes inferior aos derivados de quitosana-alginato-TNBS e 2,5 vezes inferior aos derivados preparados por imobilização em bagaço de cana.

A imobilização de LTL em diferentes suportes ativados por diferentes protocolos permitiu modular as propriedades catalíticas da enzima. A imobilização da lipase em suportes previamente ativados via glutaraldeído reduziu drasticamente a atividade específica da enzima, devido a efeitos de distorção ou limitação difusional (maior quantidade de moléculas de enzima imobilizada por grama de suporte). Em termos de atividade hidrolítica, derivados de quitosana-alginato-TNBS foram mais ativos que os de bagaço de cana. Entretanto, a imobilização da lipase em bagaço de cana produziu derivados com maior atividade específica, superior a 144 U/mgPI (PI - proteína imobilizada), seguida de quitosana-alginato-TNBS (entre 117,9 e 129,6 U/mgPI). PHB, quitosana-alginato-LAU e quitosana-alginato-TNBS produzido por coimobilização e ruptura de leveduras produziram derivados com menor atividade específica, inferior a 80 U/mgPI, conforme mostrado na Tabela 1 . Com relação à atividade recuperada, comportamento similar foi observado. Os derivados de bagaço de cana preparados por ativação com glicidol e epicloridrina apresentaram atividade recuperada acima de $75 \%$, enquanto que a atividade recuperada para os hidrogéis quitosana-alginato-TNBS oscilou entre 61,7 e $67,8 \%$.

O processo de imobilização em suportes orgânicos por diferentes protocolos permitiu melhorar sensivelmente a estabilidade térmica da lipase. Entretanto, foi verificada uma forte influência do tipo de suporte e agente de ativação na estabilidade térmica dos derivados 
preparados. A enzima solúvel possui tempo de meia-vida inferior a 4 min a $70{ }^{\circ} \mathrm{C}$. Embora a imobilização da enzima em bagaço de cana tenha produzido derivados com elevada atividade hidrolítica, a estabilização térmica foi inferior aos demais suportes, seguido de PHB e quitosana-alginato-LAU (Tabela 1). O aumento da concentração de laurinaldeído (LAU) não influenciou significativamente na estabilização da enzima. A estratégia de coimobilização de leveduras seguida de ruptura celular exerceu efeito negativo na estabilização da enzima, pois apresentou valores de estabilização inferiores aos derivados de quitosana-alginato-TNBS preparados na ausência de leveduras coimobilizadas. De acordo com a Figura 1, os derivados preparados por imobilização em hidrogéis híbridos quitosana-alginato-TNBS (preparado sem a coimobilização de leveduras) ativados pelos três agentes testados apresentaram perfis cinéticos semelhantes de inativação térmica e os tempos de meia-vida dos biocatalisadores foram próximos a $4 \mathrm{~h}$, com fator de estabilidade de 45 , ou seja, 45 vezes mais estáveis que a enzima solúvel. Os derivados preparados foram completamente inativados após $8 \mathrm{~h}$ de incubação em pH 8,0 a $70{ }^{\circ} \mathrm{C}$. De acordo com os resultados sumarizados na Tabela 1 , pode-se afirmar que foram efetuadas multi-interações covalentes entre a enzima e quitosana-alginato-TNBS ativada pelos três protocolos de ativação testados. A aplicação do hidrogel híbrido quitosana-alginato-TNBS na imobilização de lipases mostrou ser uma estratégia bastante atrativa na preparação de derivados com elevada atividade hidrolítica e altamente estáveis termicamente. Estes derivados foram selecionados para a caracterização de suas atividades catalíticas em função do $\mathrm{pH}$ do meio reacional e da temperatura de reação, bem como as suas propriedades catalíticas em meio orgânico na síntese de butirato de butila (aroma de abacaxi).

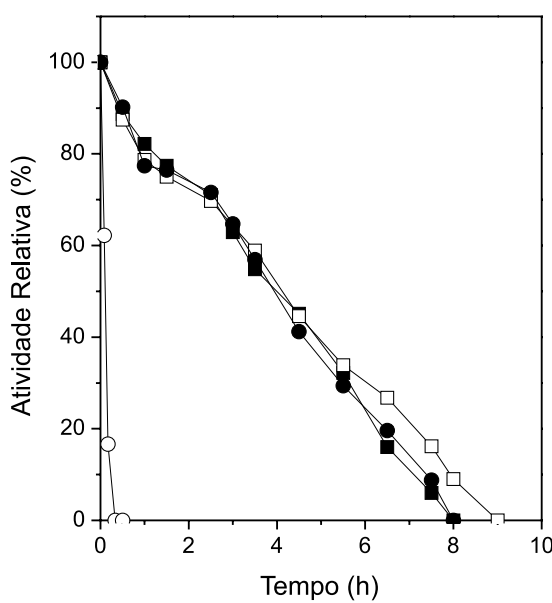

Figura 1. Cinética de inativação térmica de LTL solúvel $(\bigcirc)$ e imobilizada em quitosana-alginato-TNBS ativada com glicidol ( $\mathbf{\square})$, epicloridrina $(\square)$ e glutaraldeído (•) incubada em tampão fosfato de sódio $100 \mathrm{mM} \mathrm{pH} \mathrm{8,0} \mathrm{a} 70{ }^{\circ} \mathrm{C}$

Os suportes orgânicos testados no presente trabalho podem sofrer degradação por ação de microrganismos por se tratarem de materiais biodegradáveis. Entretanto, estes suportes foram previamente lavados com água destilada em abundância e ativados em meio altamente alcalino (solução de $\mathrm{NaOH}$ 1,7 a 2,0 mol/L). Após a ativação, estes suportes foram empregados na imobilização da enzima em meio alcalino ( $\mathrm{pH}$ 10,05). A etapa de ativação também aumenta a estabilidade destes suportes porque os seus grupos hidroxilas e aminos livres são reticulados e/ou ativados pelos ativadores testados. ${ }^{21}$ Estas condições reduzem uma possível proliferação de microrganismos no seu microambiente, o que os tornam apropriados para o processo de imobilização de enzimas.
Influência da temperatura e pH na atividade de LTL solúvel e imobilizada em quitosana-alginato-TNBS ativado por diferentes protocolos

A influência da temperatura na atividade hidrolítica da lipase solúvel e imobilizada foi determinada na faixa de $30-90{ }^{\circ} \mathrm{C}$ e os resultados são mostrados na Figura 2. A temperatura ótima de atividade hidrolítica para a enzima solúvel foi de $60^{\circ} \mathrm{C}$, enquanto que a lipase imobilizada em quitosana-alginato-TNBS-glutaraldeído aumentou em $5{ }^{\circ} \mathrm{C}$ a temperatura ótima da enzima $\left(\mathrm{T}=65^{\circ} \mathrm{C}\right)$. Os derivados preparados por ativação via glicidol e epicloridrina apresentaram atividade hidrolítica máxima a $70{ }^{\circ} \mathrm{C}$. Esses resultados mostram que a imobilização conduziu a um aumento na rigidez da estrutura da enzima.

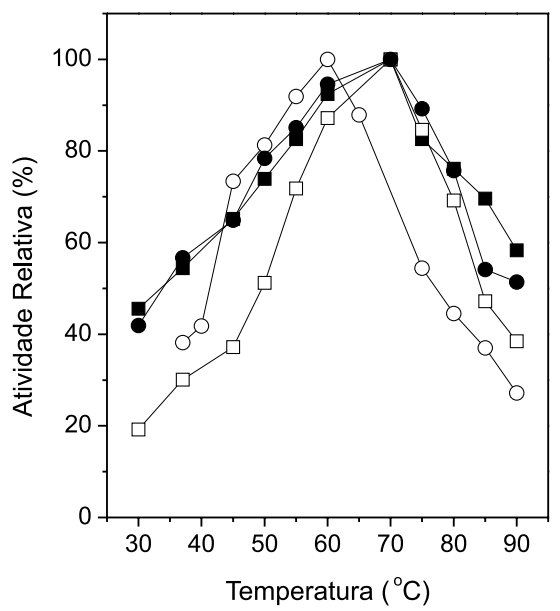

Figura 2. Influência da temperatura na atividade hidrolítica de LTL solúvel (O) e imobilizada em quitosana-alginato-TNBS ativada com glicidol (ロ), epicloridrina $(\square)$ e glutaraldeído $(\bullet)$

Conforme apresentado na Figura 3, as lipases solúvel e imobilizadas por diferentes protocolos de ativação revelaram atividades máximas em $\mathrm{pH}$ 8,0. Lipase imobilizada em hidrogel ativado com glutaraldeído foi muito mais estável na região ácida do que na região alcalina. Entretanto, as lipases solúvel e imobilizadas em suporte ativado via glioxil (glicidol e epicloridrina) foram mais estáveis na região alcalina.

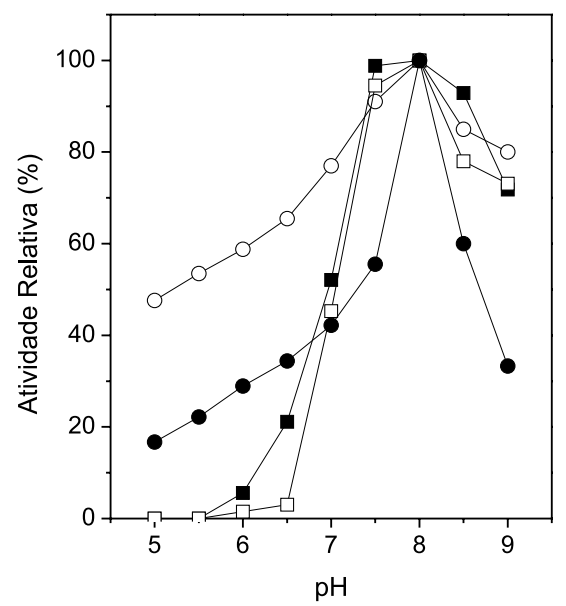

Figura 3. Influência do pH na atividade hidrolítica de LTL solúvel (O) e imobilizada em quitosana-alginato-TNBS ativada com glicidol (ם), epicloridrina $(\square)$ e glutaraldeído $(\mathbf{\bullet}$ 


\section{Síntese do éster aromatizante butirato de butila}

Os derivados preparados pela imobilização covalente multipontual de LTL em hidrogéis híbridos de quitosana-alginato-TNBS ativados por diferentes protocolos foram também testados em reações em meio orgânico na síntese do éster butirato de butila (aroma de abacaxi). A conversão do ácido butírico em butirato de butila é mostrada na Tabela 2. Embora maior concentração de proteína tenha sido imobilizada no suporte preparado por ativação glutaraldeído, duas vezes maior que os hidrogéis ativados via glioxil (Tabela 1), a conversão em butirato de butila observada foi de $42,9 \pm 3,80 \%$. Entretanto, a conversão máxima em éster aromatizante $(\approx 55 \%)$ foi obtida para as reações catalisadas pelos derivados preparados por ativação glioxil, corroborando os resultados obtidos para estes derivados em reações de hidrólise. Estes resultados também podem ser explicados pelo efeito de distorção e/ou forte limitação difusional de moléculas de lipases imobilizadas no suporte previamente ativado com glutaraldeído. Baseada nos resultados obtidos, a imobilização da lipase em hidrogéis de quitosana-alginato modificados quimicamente com TNBS é bastante atrativa na produção de importantes aditivos para a indústria de alimentos e cosméticos como butirato de butila (aroma de abacaxi).

Tabela 2. Conversão de ácido butírico em butirato de butila catalisada por LTL imobilizada em quitosana-alginato-TNBS ativada por diferentes protocolos

\begin{tabular}{cc}
\hline Agente de Ativação & Conversão $(\%)^{24 \mathrm{~h}}$ \\
\hline GLI & $57,4 \pm 3,60$ \\
EPI & $55,8 \pm 4,70$ \\
GLU & $42,9 \pm 3,80$ \\
\hline
\end{tabular}

\section{CONCLUSÕES}

Diferentes suportes orgânicos de baixo custo como PHB, bagaço de cana e hidrogéis híbridos quitosana-alginato foram testados na imobilização de LTL por diferentes protocolos. A estratégia de formação de maiores diâmetros de poros por coimobilização de leveduras, seguida de ruptura celular foi testada, porém não melhorou as propriedades catalíticas dos derivados preparados. A ativação exerceu forte influência nas propriedades catalíticas dos biocatalisadores preparados. A ativação com glutaraldeído permitiu elevada concentração de enzima imobilizada, entretanto a preparação de derivados com elevada atividade catalítica foi obtida por ativação com glicidol e epicloridrina. Estes resultados podem ser atribuídos aos efeitos de distorção e limitação difusional promovidos pelo glutaraldeído, devido à sua alta reatividade. Dentre os suportes testados na imobilização da lipase, o hidrogel híbrido quitosana-alginato modificado quimicamente com TNBS produziu derivados altamente ativos em meios aquoso e orgânico e estáveis termicamente, 45 vezes mais estáveis que a enzima solúvel. Dentre os derivados obtidos, aqueles preparados por ativação glioxil (glicidol e epicloridrina) foram mais ativos em meio orgânico na síntese do éster aromatizante butirato de butila.

\section{AGRADECIMENTOS}

Os autores agradecem à FAPESP (Processo 04/14593-4), ao CNPq e à Capes pelo suporte financeiro e à empresa Novozymes S.A. (Araucária, PR) pela doação da LTL.

\section{REFERÊNCIAS}

1. de Castro, H. F.; Mendes, A. A.; Santos, J. C.; Aguiar, C. L.; Quim. Nova 2004, 27, 146.
2. Mendes, A. A.; Oliveira, P. C.; Castro, H. F.; J. Mol. Catal. B: Enzym. 2012, 78, 119.

3. Mendes, A. A.; Castro, H. F.; Pereira, E. B.; Furigo Jr., A.; Quim. Nova 2005, 28, 296.

4. Hasan, F.; Shah, A. A.; Hameed, A.; Enzyme Microb. Technol. 2006, 39, 235.

5. Fernández-Lafuente, R.; J. Mol. Catal. B: Enzym. 2010, 62, 197.

6. Rodrigues, R. C.; Fernández-Lafuente, R.; J. Mol. Catal. B: Enzym. 2010, 64, 1.

7. Rodrigues, R. C.; Fernández-Lafuente, R.; J. Mol. Catal. B: Enzym. 2010, 66, 15.

8. Sharma, D.; Sharma, B.; Shukla, A. K.; Biotechnology 2011, 10, 23.

9. Sharma, R.; Chisti, Y.; Banerjee, U. C.; Biotechnol. Adv. 2001, 19, 627.

10. Al-Zuhair, S.; Almenhali, A.; Hamad, I.; Alshehhi, M.; Alsuwaidi, N.; Mohamed, S.; Renew. Energy 2011, 36, 2605.

11. Chen, H.; Chen, G. Q.; Renew. Energy 2011, 36, 1374.

12. López-Gallego, F.; Montes, T.; Fuentes, M.; Alonso, N.; Grazú, V.; Betancor, L.; Guisán, J. M.; Fernández-Lafuente, R.; J. Biotechnol. 2005, 116, 1 .

13. Villeneuve, P.; Muderhwa, J. M.; Graille, J.; Haas, M. J.; J. Mol. Catal. B: Enzym. 2000, 9, 113.

14. Dalla-Vecchia, R.; Nascimento, M. G.; Soldi, V.; Quim. Nova 2004, 27, 623.

15. Jegannathan, K. R.; Abang, S.; Poncelet, D.; Chan, E. S.; Ravindra, P.; Crit. Rev. Biotechnol. 2008, 28, 253.

16. Cardoso, C. L.; de Moraes, M. C.; Cass, Q. B.; Quim. Nova 2009, 32, 175.

17. Mateo, C.; Palomo, J. M.; Fernández-Lorente, G.; Guisán, J. M.; Fernández-Lafuente, R.; Enzyme Microb. Technol. 2007, 40, 1451.

18. Mateo, C.; Palomo, J. M.; Fuentes, M.; Betancor, L.; Grazú, V.; LópezGallego, F.; Pessela, B. C. C.; Hidalgo, A.; Fernández-Lorente, G.; Fernández-Lafuente, R.; Guisán, J. M.; Enzyme Microb. Technol. 2006, 39, 274.

19. Adriano, W. S.; Mendonça, D. B.; Rodrigues, D. S.; Mammarella, E. J.; Giordano, R. L. C.; Biomacromolecules 2008, 9, 2170.

20. Mendes, A. A.; Barbosa, B. C. M.; Silva, M. L. C. P.; Castro, H. F.; Biocatal. Biotransform. 2007, 25, 393.

21. Mendes, A. A.; Castro, H. F.; Rodrigues, D. S.; Adriano, W. S.; Tardioli, P. W.; Mammarella, E. J.; Giordano, R. C.; Giordano, R. L. C.; J. Ind. Microbiol. Biotechnol. 2011, 38, 1055.

22. Mendes, A. A.; Giordano, R. C.; Giordano, R. L. C.; Castro, H. F.; J. Mol. Catal. B: Enzym. 2011, 68, 109.

23. Mendes, A. A.; Oliveira, P. C.; Vélez, A. M.; Giordano, R. C.; Giordano, R. L. C.; Castro, H. F.; Int. J. Biol. Macromol. 2012, 50, 503.

24. Mendes, A. A.; Oliveira, P. C.; Castro, H. F.; Giordano, R. L. C.; Quim. Nova 2011, 34, 831.

25. Mendes, A. A.; Rodrigues, D. S.; Filice, M.; Fernández-Lafuente, R.; Guisán, J. M.; Palomo, J. M.; Tetrahedron 2008, 64, 10721.

26. Rodrigues, D. S.; Mendes, A. A.; Filice, M.; Fernández-Lafuente, R.; Guisán, J. M.; Palomo, J. M.; J. Mol. Catal. B: Enzym. 2009, 58, 36.

27. Fernández-Lorente, G.; Godoy, C. A.; Mendes, A. A.; López-Gallego, F.; Grazú, V.; de las Rivas, B.; Palomo, J. M.; Hermoso, J.; FernándezLafuente, R.; Guisán, J. M.; Biomacromolecules 2008, 9, 2553.

28. Rodrigues, D. S.; Mendes, A. A.; Adriano, W. S.; Gonçalves, L. R. B.; Giordano, R. L. C.; J. Mol. Catal. B: Enzym. 2008, 51, 100.

29. Palomo, J. M.; Ortiz, C.; Fernández-Lorente, G.; Fuentes, M.; Guisán, J. M.; Fernández-Lafuente, R.; Enzyme Microb. Technol. 2005, 36, 447.

30. Betancor, L.; López-Gallego, F.; Hidalgo, A.; Alonso-Morales, N.; Dellamora-Ortiz, G.; Mateo, C.; Fernández-Lafuente, R.; Guisán, J. M.; Enzyme Microb. Technol. 2006, 39, 877.

31. Simões, A. S.; Mori, R. Y.; Faria, R.; Castro, H. F.; Mendes, A. A.; Quim. Nova 2011, 34, 33. 
32. Malcata, F. X.; Reyes, H. R.; Garcia, H. S.; Hill Jr, C. G.; Amundson, C. H.; J. Am. Oil Chem. Soc. 1990, 67, 890.

33. Palomo, J. M.; Muñoz, G.; Fernández-Lorente, G.; Mateo, C.; Fernández-Lafuente, R.; Guisán, J. M.; J. Mol. Catal. B: Enzym. 2002, 19-20, 279.

34. Paula, A. V.; Moreira, A. B. R.; Braga, L. P.; Bruno, L. M.; Castro, H. F.; Quim. Nova 2008, 31, 35.

35. Séverac, E.; Galy, O.; Turon, F.; Pantel, C. A.; Condoret, J. S.; Monsan, P.; Marty, A.; Enzyme Microb. Technol. 2011, 48, 61.

36. http://www.sigmaaldrich.com/catalog/product/sigma/ cl6b200?lang=pt\&region=BR, acessada em Dezembro 2012.
37. Bradford, M. M.; Anal. Biochem. 1976, 72, 248.

38. Soares, C. M. F.; Castro, H. F.; Zanin, G. M.; Moraes, F. F.; Appl. Biochem. Biotechnol. 1999, 77/79, 745.

39. Guisán, J. M.; Enzyme Microb. Technol. 1988, 10, 375.

40. Beppu, M. M.; Arruda, E. J.; Vieira, R. S.; Santos, N. N.; J. Memb. Sci. 2004, 240, 227.

41. Fernández-Lafuente, R.; Rosell, C. M.; Rodríguez, V.; Santana, C.; Soler, G.; Bastida, A.; Guisán, J. M.; Enzyme Microb. Technol. 1993, 15,546 . 